Abstract-Underwater video sampling has become a common approach to index fish abundance and diversity, but little has been published on determining how much video to read. We used video data collected over a period of 6 years in the Gulf of Mexico to examine how the number of video frames read affects accuracy and precision of fish counts and estimates of species richness. To examine fish counts, we focused on case studies of red snapper (Lutjanus campechanus), vermilion snapper (Rhomboplites aurorubens), and scamp (Mycteroperca phenax). Using a bootstrap framework, we found that fish counts were unbiased when at least 5 of 1201 video frames within a 20-min video were read. The relative patterns of coefficients of variation $(\mathrm{CVs})$ were nearly identical among species and declined as an inverse power function. Initial decreases in CVs were rapid as the number of frames read increased from 1 to 50. However, subsequent declines were modest, decreasing only by $\sim 50 \%$ when the number of frames read increased by $300 \%$. Estimated species richness increased asymptotically as the number of frames read increased from 25 to 200 frames, and reading 50 frames documented $86 \%$ of the species observed across all 1201 frames. Lastly, we used a generalized additive model to show that the most likely species to be missed were fast-swimming fishes that are solitary or form relatively small schools. Our results indicate that the most efficient use of resources (i.e., maximum information gained at the lowest cost) would be to read $\sim 50$ frames from each video.

Manuscript submitted 30 July 2013. Manuscript accepted 13 November 2014. Fish. Bull. 113:15-26 (2015).

doi: 10.7755/FB.113.1.2

The views and opinions expressed or implied in this article are those of the author (or authors) and do not necessarily reflect the position of the National Marine Fisheries Service, NOAA.

\title{
Estimating relative abundance and species richness from video surveys of reef fishes
}

\author{
Nathan M. Bacheler (contact author) \\ Kyle W. Shertzer \\ Email address for contact author: nate.bacheler@noaa.gov \\ Beaufort Laboratory \\ Southeast Fisheries Science Center \\ National Marine Fisheries Service, NOAA \\ 101 Pivers Island Road \\ Beaufort, North Carolina 28516
}

Underwater video sampling has become a ubiquitous approach around the world to index the abundance of marine fish and invertebrate species and to quantify marine biodiversity (see reviews by Somerton and Gledhill, 2005; Murphy and Jenkins, 2010). Although numerous underwater video approaches and techniques have been used to index abundance, many researchers now employ some version of a stationary point-count method with baited remote underwater video stations (BRUVS) (Willis et al., 2000; Cappo et al., 2004). BRUVS sampling has many advantages: 1) it is nonextractive and, therefore, preferred in no-take areas, 2) is less size- or species-selective than other baited gears, 3) can sample deeper waters more easily than diver surveys and do so at lower costs than can autonomous underwater vehicles, 4) provides a permanent record available to be reviewed for accuracy by multiple readers, and 5) can capture habitat characteristics of a survey site and behavioral interactions among species (Silveira et al., 2003; Wells et al., 2008; Langlois et al., 2010; Bacheler et al., 2013).

Nearly all BRUVS studies now use an approach called MinCount (or MaxN or MaxNo) to index the number of individuals of various species present at a site (Ellis and DeMartini, 1995; Mur- phy and Jenkins, 2010). MinCount is defined as the maximum number of individuals (of each species) present in a single frame during a viewing interval, and this approach is popular because it provides a conservative estimate of the number of individuals of each species present at a site (Ellis and DeMartini, 1995; Willis and Babcock, 2000; Merritt et al, 2011). However, MinCount may be nonlinearly related to actual abundance because it measures a smaller and smaller proportion of individuals present at a site as abundance increases (Conn, 2011; Schobernd et al., 2014). Instead, Conn (2011) proposed an alternative approach, MeanCount, which is calculated as the mean number of individuals observed in a series of frames over a viewing interval. Schobernd et al. (2014) found that MeanCount tracked true abundance linearly with levels of precision similar to that of MinCount. A linear relationship is highly desirable for developing indices of abundance in stock assessment models (Kimura and Somerton, 2006).

A logical next step in the development of the MeanCount approach for indexing fish abundance, as well as in estimating species richness, is to determine the optimal number of frames to be read over a given time interval. Previous studies have shown a strong relationship between 


\section{Table 1}

Number of video samples $(N)$ included in the analyses of reef fishes in the northern Gulf of Mexico, as well as the range of dates, latitudes, and longitudes covered by the samples in 2001-2002 and 2004-2007.

\begin{tabular}{lrccc}
\hline Year & $N$ & Date range & Latitude range $\left({ }^{\circ} \mathrm{N}\right)$ & Longitude range $\left({ }^{\circ} \mathrm{W}\right)$ \\
\hline 2001 & 42 & $6 / 14-6 / 22$ & $27.79-28.35$ & $91.03-93.82$ \\
2002 & 260 & $2 / 22-5 / 30$ & $24.50-30.00$ & $84.26-96.78$ \\
2004 & 169 & $4 / 8-6 / 22$ & $24.59-30.13$ & $82.97-96.30$ \\
2005 & 350 & $4 / 20-7 / 29$ & $24.51-30.13$ & $82.77-96.53$ \\
2006 & 333 & $4 / 16-8 / 4$ & $24.53-30.14$ & $82.77-96.78$ \\
2007 & 389 & $4 / 22-8 / 13$ & $24.50-30.13$ & $82.77-96.77$ \\
& & & & \\
\hline
\end{tabular}

the time spent surveying and the number of taxa encountered for a wide variety of fish and wildlife species (Fuller and Langslow, 1984; St. John et al., 1990; Barker et al., 1993; Gledhill, 2001), and new methods can account for detection probabilities of $<1$ when estimating species richness (Nichols et al., 1998; Johnson et al., 2013). Reading more frames will certainly provide more information but will also bring increased costs associated with the additional time and effort required (Rotherham et al., 2007; Al-Chokhachy et al., 2009).

Our objective was to examine the tradeoff between minimizing the effort needed to read videos and maximizing the information obtained. We focused our analyses on 2 primary response variables, each as a function of the number of video frames read. First, we examined potential bias and precision of MeanCount for 3 economically important reef fish species in the Gulf of Mexico. Second, we examined estimates of species richness, defined here as the number of species observed in a video. The results provide general guidance regarding the amount of effort that should be expended to read underwater videos in diverse aquatic systems.

\section{Materials and methods}

\section{Data}

We analyzed video data from a long-term reef fish monitoring program conducted within U.S. waters of the Gulf of Mexico. These data were collected by the Southeast Fisheries Science Center, National Marine Fisheries Service, in 2001-2002 and 2004-2007. A 4-camera array was deployed with a soak time of 40 min on hard-bottom habitats throughout the sampling range (Table 1) during the reef fish video survey of the Southeast Area Monitoring and Assessment Program. Four Sony DCR-VX2000 ${ }^{1}$ (Sony Corp., Tokyo) camcorders were mounted orthogonally on a metal array, fac-

\footnotetext{
${ }^{1}$ Mention of trade names or commercial companies is for identification purposes only and does not imply endorsement by the National Marine Fisheries Service, NOAA.
}

ing outward, at a height of $30 \mathrm{~cm}$ above the bottom (for more details, see Gledhill ${ }^{2}$ ). Each array was baited with approximately $0.5 \mathrm{~kg}$ of squid (Illex spp.) in a mesh bag and deployed during daylight hours only. These particular years were selected because they were the most recent years for which data were available before a significant methodological change occurred in video reading procedures.

The reef fish video survey was developed to index reef fish populations and was typically conducted in the spring and summer on shelf-edge reefs from south Texas to the Dry Tortugas in Florida (Fig. 1). A 2-stage sampling design was used to minimize travel time between stations because the survey area was large. For the first stage, we used a stratified random sampling design of randomly selected blocks, each of which was $10^{\prime}$ of latitude by $10^{\prime}$ of longitude in size. Blocks were stratified by 4 geographic regions and by the amount of reef habitat (low or high) present in each block; each block was subdivided into a grid of cells that were 0.19 $\mathrm{km}$ by $0.19 \mathrm{~km}$. For the second stage of sampling, cells were randomly selected from within each block. The number of grid cells available for random selection varied depending on how much known reef area was contained in the sampled block.

From each 40-min deployment, 1 of 4 videos was randomly selected, and $20 \mathrm{~min}$ of that video was analyzed beginning at the point when video visibility was sufficiently clear for identification of taxa. Fish shape, anatomical features, coloration, and swimming behaviors were used to identify individuals to genus and species levels by using field guides (e.g., Hoese and Moore, 1998; McEachran and Fechhelm, 1998; Carpenter, 2002; Humann and Deloach, 2002; McEachran and Fechhelm, 2005). Video frames were examined every second dur-

\footnotetext{
${ }^{2}$ Gledhill, C. T., G. W. Ingram Jr., K. R. Rademacher, P. Felts, B. Trigg, and L. Lombardi-Carlson. 2006. SEAMAP reef fish survey of offshore banks: yearly indices of abundance of red grouper (Epinephelus morio). SEDAR 12-DW-6, 12 p. [Available from http://www.sefsc.noaa.gov/sedar/download/S12\%20DW06\%20Video-survey.pdf?id=DOCUMENT, accessed 31 March 2014.]
} 


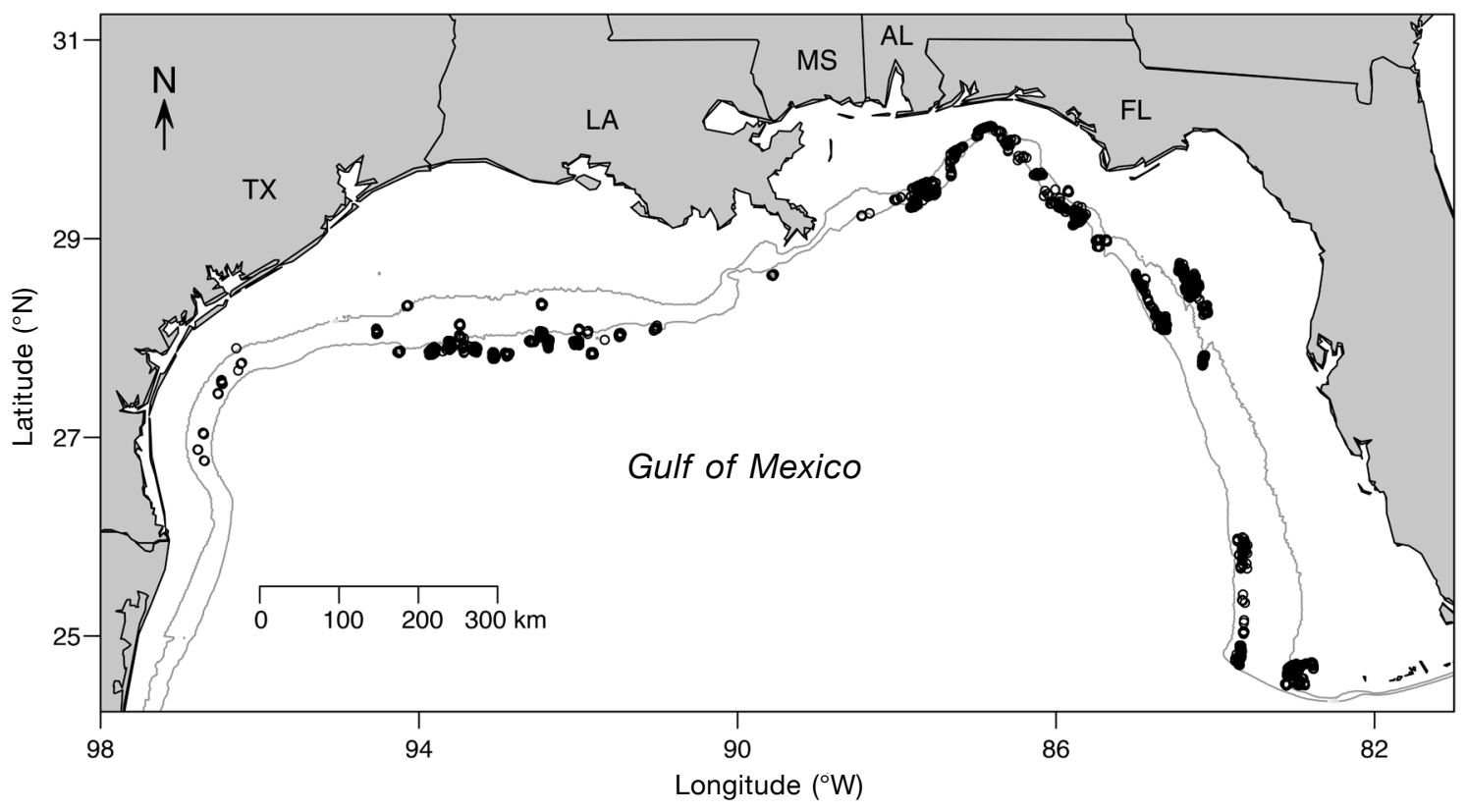

Figure 1

Sampling locations (o) where video was collected during the National Marine Fisheries Service's reef fish video survey in the Gulf of Mexico in 2001-2002 and 2004-2007 as part of its Southeast Area Monitoring and Assessment Program. The light gray bathymetric contour lines indicate depths of 50 and $100 \mathrm{~m}$, respectively. Note that symbols overlap in many cases.

ing the interval from $t=0$ to $t=20 \mathrm{~min}$, resulting in analysis of 1201 frames. Species were recorded if they were listed in the fishery management plans of the Gulf of Mexico or South Atlantic Fishery Management Council or if commercial or recreational landings were known to exist. The resulting list of observed taxa included 210 species (a group, hereafter, called priority species). The time each individual fish swam into and out of view (i.e., time in-time out) was recorded for each priority species. Our analysis included only those video samples in which at least one priority species was seen at some point during the $20 \mathrm{~min}$. On the basis of these criteria, 1543 videos were included in our analyses.

\section{MeanCount bias and precision}

For a single video $v$, the MeanCount of a species across video frames was defined with the following equation:

$$
\operatorname{MeanCount}_{v, F}=\frac{\left(\sum_{f=1}^{F} n_{f}\right)}{F},
$$

where $n_{f}=$ the number of individuals observed in frame $f$; and

$F=$ the total number of frames read.

To examine how MeanCount relates to the number of frames read, we chose as case studies 3 ecologically and commercially important focal species: red snapper (Lutjanus campechanus), vermilion snapper (Rhomboplites aurorubens), and scamp (Mycteroperca phenax). These species were chosen because they vary substantially in terms of body size and schooling behavior. Scamp are generally solitary, red snapper often form small groups, and vermilion snapper often form large groups. Vermilion snapper are also much smaller than red snapper or scamp. Misidentification of these species is very unlikely because of their distinct body shapes and swimming behaviors. Of the 1543 videos examined in our study, red snapper were observed in 375 videos, vermilion snapper in 217, and scamp in 466. MeanCount was computed only from those videos in which the focal species was observed.

For each species, the true MeanCount for each video (MeanCount $\mathrm{v}_{\mathrm{v}, \text { true }}$ ) was computed from the full sampling universe of 1201 frames. That true value was then estimated with a subset of frames with a possible sample size $(F)$ from the interval [1, 200]. The sampling was conducted as follows. First, a list of frames $(n=200)$ was drawn at random and without replacement from the full set of 1201 frames. Then, the first frame of the list $(F=1)$ was used to compute MeanCount v, $1_{1}$. Next, the second frame $(F=2)$ was included along with the first to compute MeanCount $\mathrm{v}_{\mathrm{v}, 2}$, and so forth until all 200

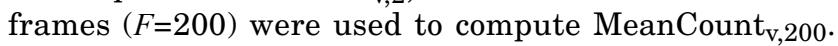

We quantified bias and precision in estimates of MeanCount with a bootstrap procedure. In the bootstrap, the previously described sampling approach was repeated 1000 times. That is, for each bootstrap iteration $b$, a new set of 200 frames was drawn to com- 
pute MeanCount for every value of $F=[1,2, \ldots, 200]$ frames. Therefore, we computed 1000 values for every MeanCount $\mathrm{v}_{\mathrm{v}, \mathrm{F}}$, a choice that expanded our previous nomenclature to MeanCount $\mathrm{b}_{\mathrm{b}, \mathrm{v}, \mathrm{F}}$, where $b$ represents a single bootstrap replicate, $v$ represents a particular video sampling event, and $F$ represents the number of frames read.

For each species, we quantified error in estimation using mean relative error (MRE). On the basis of 1000 bootstrap replicates, we computed the MRE for each video in which a species was observed and for each number of frames read with the following equation:

$M R E_{v, F}=\frac{\sum_{B=1}^{1000}\left(\frac{\text { MeanCount }_{b, v, F}-\text { MeanCount }_{v, \text { true }}}{\text { MeanCount }_{v, \text { true }}}\right)}{1000}$.

In addition to their use in determining MRE, we used the bootstrap replicates to compute the coefficient of variation (CV) for each video and for each number of frames read, $\mathrm{CV}_{\mathrm{v}, \mathrm{F}}$. For graphical presentation, these $\mathrm{CVs}$ were scaled to their minima (which occurred at the largest sample size, $F=200$ ) to demonstrate the proportional decline in variability in estimates as sample size increased. To quantify the expected response, mean CVs across videos $\left(\overline{\mathrm{CV}}_{\mathrm{F}}\right)$ were related to the number of frames through the use of a power function, $\overline{C V}_{\mathrm{F}}=a F^{\mathrm{b}}$, where $a$ and $b$ are parameters. These parameters were estimated in log-log space through linear regression, with the following equation:

$$
\log \left(\overline{C V}_{F}\right)=a^{\prime}+b \log (F),
$$

where $a^{\prime}=\log (a)$.

Then, the power function could be inverted to provide the number of frames necessary to achieve a desired mean $\mathrm{CV}$ :

$$
F=\sqrt[b]{\overline{C V} \bar{F}_{F} / a}
$$

\section{Species richness}

The procedure for estimating species richness for priority species was similar to the one for estimating MeanCount. However, when estimating species richness, we used all 1543 videos. We first computed the true species richness observed in each video $\left(R_{\mathrm{v}, \text { true }}\right)$ as the total number of priority species observed across all 1201 frames. Note that $R_{\mathrm{v} \text {,true }}$ is not necessarily the true species richness at a particular site but rather is the species richness observed in an entire 20-min video. That true value was then estimated by tabulating the species richness observed during each increment of the number of frames read, $F=[1,2, \ldots, 200]$. As before, uncertainty in the estimation was quantified with a bootstrap procedure with 1000 replicates, where each replicate $(b)$ contained a set of 200 frames drawn at random and without replacement from the original 1201 frames. Therefore, for each video, we generated
1000 estimates of species richness for each number of frames read, $R_{\mathrm{b}, \mathrm{v}, \mathrm{F}}$.

Once computed, the estimates of species richness were used to evaluate how increasing the number of frames read $(F)$ affected the detection of species known to be present in a video. For this evaluation, we used the average number of species detected across bootstrap replicates, scaled to the true value, with the following equation:

$$
P_{v, F}=\frac{\left(\sum_{b=1}^{1000} R_{b, v, F}\right) / 1000}{R_{v, \text { true }}} .
$$

Therefore, $P_{\mathrm{v}, \mathrm{F}}$ is a proportion equal to zero if no species known to be present were detected on average or equal to one if all possible species were detected on average.

To better understand the estimates of species richness, we related the probability of being observed to behavioral characteristics of those species in videos. Specifically, we considered 2 characteristics of each priority species $(s): 1)$ the mean number of individuals $\left(N_{\mathrm{S}}\right)$ seen in a video and 2$)$ the mean duration $\left(D_{\mathrm{s}}\right.$; in seconds) each individual was observed in the videos. These mean values for each species were taken across videos in which a particular species was present. To remove rare species for which mean characteristics may be poorly estimated, species were included in this analysis only if observed in at least 10 videos. We then used a generalized additive model (GAM) to relate $N_{\mathrm{s}}$ and $D_{\mathrm{s}}$, and their interaction, to the proportion of bootstrap replicates $\left(Y_{\mathrm{s}}\right)$ in which species $s$ was observed, from all videos where the species was present and where the number of frames read was $F=25$. We used 25 frames in this study to provide a meaningful contrast across families in the probability of being observed; making such distinctions is important for detecting the effects of predictor variables. All priority species were included in this analysis. Before fitting the GAM, the response variable $Y_{\mathrm{s}}$ was transformed from probability space by using the arcsin squareroot transformation to achieve approximate normality, and predictor variables were taken in log space:

$$
\begin{gathered}
\arcsin \left(\sqrt{Y_{s}}\right)= \\
g_{1}\left(\log \left(N_{\mathrm{s}}\right)\right)+g_{2}\left(\log \left(D_{s}\right)\right)+g_{3}\left(\log \left(N_{s}\right),\left(\log \left(D_{s}\right)\right),\right.
\end{gathered}
$$

where $g_{1}, g_{2}$, and $g_{3}$ represent spline functions.

The GAM approach strikes a balance between more simple and more complicated models, and it was chosen for its flexibility and for providing a straightforward interpretation of results. The GAM was implemented in the $\mathrm{R}$ programming language, vers. 2.15.1 ( $\mathrm{R}$ Core Team, 2012) with the mgcv library (Wood, 2006). For presentation, the fitted response was transformed back into probability space by squaring the sine of the response.

Lastly, we summarized the mean duration in a $20-\mathrm{m}$ video segment, mean number of individuals in each vid- 
Table 2

Mean duration and standard error of the mean (SE), measured in seconds (s), of individual fishes in video, mean number of individuals in videos, and mean probability that a fish species would be seen in a video segment (for those videos in which that species occurred) summarized by family for only those species seen in at least 10 videos from footage collected during the National Marine Fisheries Service's reef fish video survey conducted in the Gulf of Mexico in 2001-2002 and 2004-2007 as part of its Southeast Area Monitoring and Assessment Program. Mean probability of being seen in a video was calculated for each species as the mean proportion of videos in which a species was observed (on the basis of 25 randomly selected frames) over all videos in which that species was present. Note that the family names for Labridae, Serranidae, and Scaridae follow the Integrated Taxonomic Information System (http://www.itis.gov). Standard errors of the means (SE) are provided in parentheses.

\begin{tabular}{|c|c|c|c|c|c|}
\hline Family & Common name & $\begin{array}{l}\text { Number of } \\
\text { species }\end{array}$ & $\begin{array}{c}\text { Mean duration } \\
(\mathrm{s})\end{array}$ & $\begin{array}{l}\text { Mean number } \\
\text { of individuals }\end{array}$ & $\begin{array}{l}\text { Probability of being } \\
\text { seen in video }\end{array}$ \\
\hline Opistognathidae & jawfishes & 1 & 504 & 22 & 1.00 \\
\hline Priacanthidae & bigeyes & 2 & $921(\mathrm{SE} 127)$ & $3(\mathrm{SE} 1)$ & $0.99(\mathrm{SE} 0.01)$ \\
\hline Holocentridae & squirrelfishes & 1 & 132 & 10 & 0.96 \\
\hline Pomacanthidae & angelfishes & 5 & 44 (SE7) & $16(\mathrm{SE} \mathrm{9)}$ & $0.85(\mathrm{SE} 0.03)$ \\
\hline Balistidae & triggerfishes & 3 & $66(\mathrm{SE} 40)$ & $11(\mathrm{SE} 4)$ & $0.84(\mathrm{SE} 0.07)$ \\
\hline Pomacentridae & damselfishes & 5 & $35(\mathrm{SE} 6)$ & $23(\mathrm{SE} 7)$ & $0.84(\mathrm{SE} 0.04)$ \\
\hline Labridae & wrasses & 7 & $15(\mathrm{SE} 2)$ & $31(\mathrm{SE} 8)$ & $0.80(\mathrm{SE} 0.06)$ \\
\hline Serranidae & sea basses and groupers & 23 & $30(\mathrm{SE} 2)$ & $12(\mathrm{SE} 2)$ & $0.78(\mathrm{SE} 0.02)$ \\
\hline Chaetodontidae & butterflyfishes & 3 & 31 (SE 3) & $11(\mathrm{SE} 2)$ & $0.77(\mathrm{SE} 0.03)$ \\
\hline Malacanthidae & tilefishes & 2 & 28 (SE 11) & $8(\mathrm{SE} 0)$ & $0.76(\mathrm{SE} 0.05)$ \\
\hline Sparidae & porgies & 6 & $14(\mathrm{SE} 2)$ & $22(\mathrm{SE} 10)$ & $0.75(\mathrm{SE} 0.03)$ \\
\hline Acanthuridae & surgeonfishes & 3 & $26(\mathrm{SE} 6)$ & $6(\mathrm{SE} 1)$ & $0.73(\mathrm{SE} 0.02)$ \\
\hline Haemulidae & grunts & 4 & 25 (SE 8) & $22(\mathrm{SE} 6)$ & $0.73(\mathrm{SE} 0.05)$ \\
\hline Lutjanidae & snappers & 7 & $12(\mathrm{SE} 1)$ & 37 (SE 9) & $0.73($ SE 0.04$)$ \\
\hline Scaridae & parrotfishes & 4 & $23(\mathrm{SE} 2)$ & 13 (SE 5) & $0.71(\mathrm{SE} 0.05)$ \\
\hline Tetraodontidae & puffers & 2 & $25(\mathrm{SE} 7)$ & $4(\mathrm{SE} 1)$ & $0.64(\mathrm{SE} 0.13)$ \\
\hline Mullidae & goatfishes & 2 & $11(\mathrm{SE} 4)$ & $14(\mathrm{SE} 6)$ & $0.60(\mathrm{SE} 0.00)$ \\
\hline Muraenidae & morays & 2 & $40(\mathrm{SE} 4)$ & $4(\mathrm{SE} 2)$ & $0.60(\mathrm{SE} 0.07)$ \\
\hline Carangidae & jacks & 6 & $6(\mathrm{SE} 1)$ & $14(\mathrm{SE} 2)$ & $0.40(\mathrm{SE} 0.04)$ \\
\hline Sphyraenidae & barracudas & 1 & 18 & 4 & 0.34 \\
\hline Scombridae & mackerels & 1 & 5 & 2 & 0.17 \\
\hline
\end{tabular}

eo segment, and probability of being observed in each video for each of the families of fishes included in the analysis described previously in this section (Table 2). The purpose of including this table is to inform readers working in tropical and subtropical oceans about those groups of species they are likely to see and those groups that they are likely to miss if adopting a MeanCount approach where a subset of frames is read.

\section{Results}

\section{MeanCount bias and precision}

The MeanCount estimator behaved similarly for the 3 species that we used as case studies. The central tendency across bootstrap replicates, represented by mean MeanCount, converged rapidly for red snapper, vermilion snapper, and scamp as the number of frames read increased (Fig. 2). MeanCount values for scamp and red snapper were less variable than the results for vermilion snapper (on the basis of $5^{\text {th }}$ and $95^{\text {th }}$ percen- tiles), and variability for all 3 species decreased when more frames were read (Fig. 2).

Across all sampling events (i.e., all 20-min videos analyzed) in which the focal species was observed, there were no obvious biases in MeanCount for red snapper, vermilion snapper, or scamp at any level of sampling intensity for 25 to 200 frames read (Fig. 3). The variance for each species decreased as the number of frames read increased, a finding consistent with the results of the individually selected video analysis previously described (Fig. 3). Furthermore, the variance surrounding MeanCount was approximately 50\% lower for scamp than for either red snapper or vermilion snapper (Fig. 3).

The relative patterns of MeanCount CVs were nearly identical among the 3 species (Fig. 3). As the number of frames increased from 1 to 200, the decrease in CV was initially rapid and then more gradual as more frames were read (Fig. 3). Because of this pattern, the largest reduction in CVs for all 3 species occurred as the number of frames read increased from 1 to 50 . When frames read increased from 50 to 200 (i.e., 


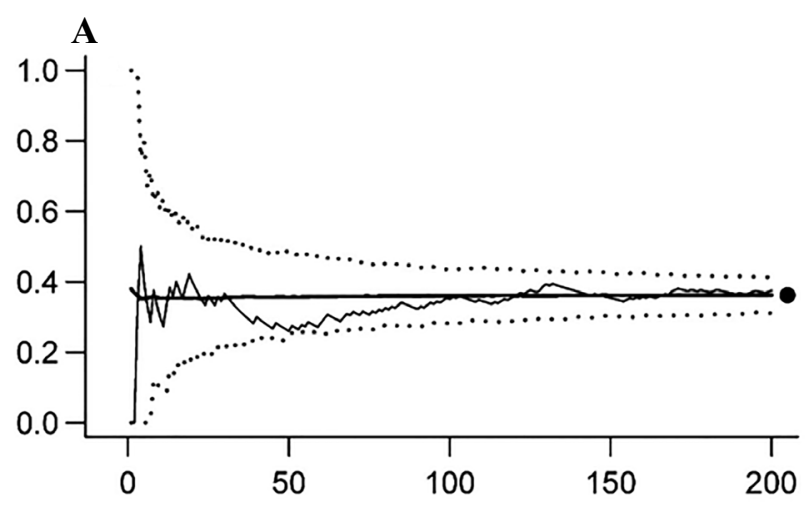

B

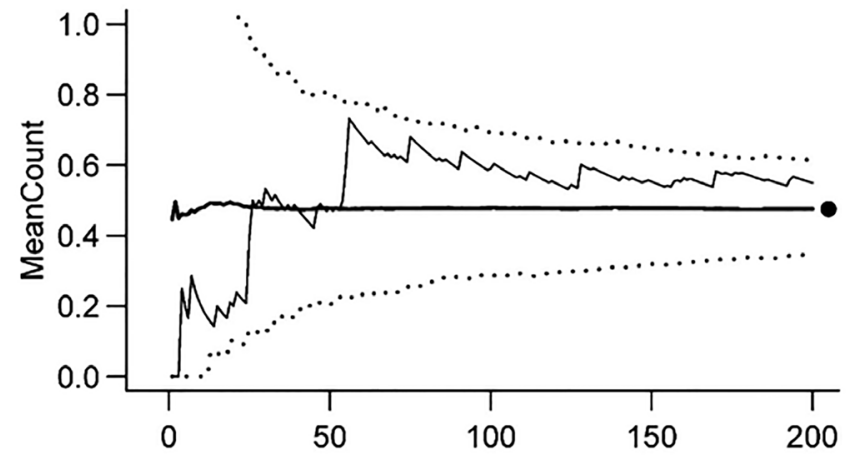

C

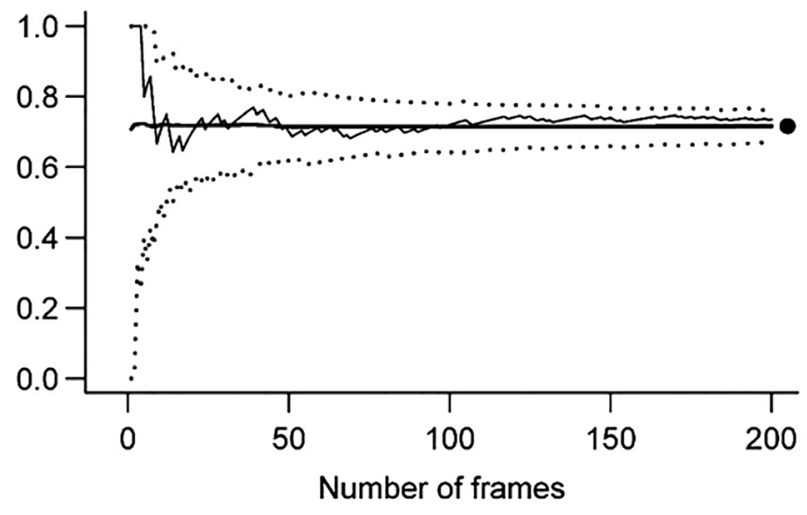

Figure 2

MeanCount, which is calculated as the mean number of individual fish observed in a series of frames over a viewing interval, of a single sampling event (i.e., a 20-min video segment) in the northern Gulf of Mexico as a function of the number of video frames that were read for (A) red snapper (Lutjanus campechanus), (B) vermilion snapper (Rhomboplites aurorubens), and (C) scamp (Mycteroperca phenax). In each panel, the heavy solid line represents the mean of 1000 bootstrap replicates, the lower dotted line represents the $5^{\text {th }}$ percentile, the upper dotted line represents the $95^{\text {th }}$ percentile, the thin solid line is a single bootstrap iteration, and the filled circle on the right is the true MeanCount across all 1201 frames that were analyzed for this study.
$300 \%$ increase in frames read), CVs only declined by approximately $50 \%$ for all 3 species.

In all cases, the relationship between mean $\mathrm{CVs}$ and number of frames read was described well by power functions (coefficient of determination $\left[r^{2}\right]>0.99 ; P<0.0001$ for $F$-statistics). Among the 3 species, the estimated relationships show differences in scale $\left(a^{\prime}\right)$ but similar rates of decline (b). The mean estimates of parameters and standard errors of the mean (SE) were $a^{\prime}=1.324$ (SE 0.004) and $b=-0.525$ (SE 0.001) for red snapper, $a^{\prime}=1.585$ (SE 0.004) and $b=-0.524$ (SE 0.001) for vermilion snapper, and $a^{\prime}=0.981$ (SE 0.004) and $b=-0.525$ (SE 0.001) for scamp. Because the rates of decline were similar across species, the same number of frames could be read for each if the goal is to achieve a proportional reduction in CV from each species' maximum (which occurred at $F=1$ ). However, if the goal is to achieve a particular CV, then each species would require a different number of frames read. For example, a CV of 0.4 would require $F=71$ for red snapper, $F=119$ for vermilion snapper, and $F=37$ for scamp.

\section{Species richness}

For illustration, we chose 3 example videos with varying levels of species richness to show general patterns in estimates of species richness. In these example videos, the estimated species richness (number of species observed) increased asymptotically as more frames were read (Fig. 4). Although these 3 videos were chosen simply as examples, they show that the estimates of species richness increased stepwise as the number of frames read was incremented. That is, with the inclusion of each additional frame read, the species count either remained the same if that frame contained no new species or it increased by the number of new species observed. In these examples, the median estimate captured $100 \%$ of the species present by around 50 frames for the videos with 3 or 7 species observed but not until around 100 frames for the video that contained 17 species (Fig. 4).

Across all 1543 videos, the proportion of species observed increased with sampling intensity. Most species (median proportion $=0.75$ ) were observed in each video when only 25 of the 1201 frames were read, and the median proportion increased when 50 frames (0.86), 100 frames (0.95), or 200 frames (0.99) were read (Fig. 5). On the basis of the interquartile range, however, there was substantial variability among videos, particularly when fewer than 100 frames were read (Fig. 5). When 100 or more frames were read, the variability was lower but some rare species in some videos were still missed.

The GAM explained $87.2 \%$ of the deviation in the probability that a species would be observed 


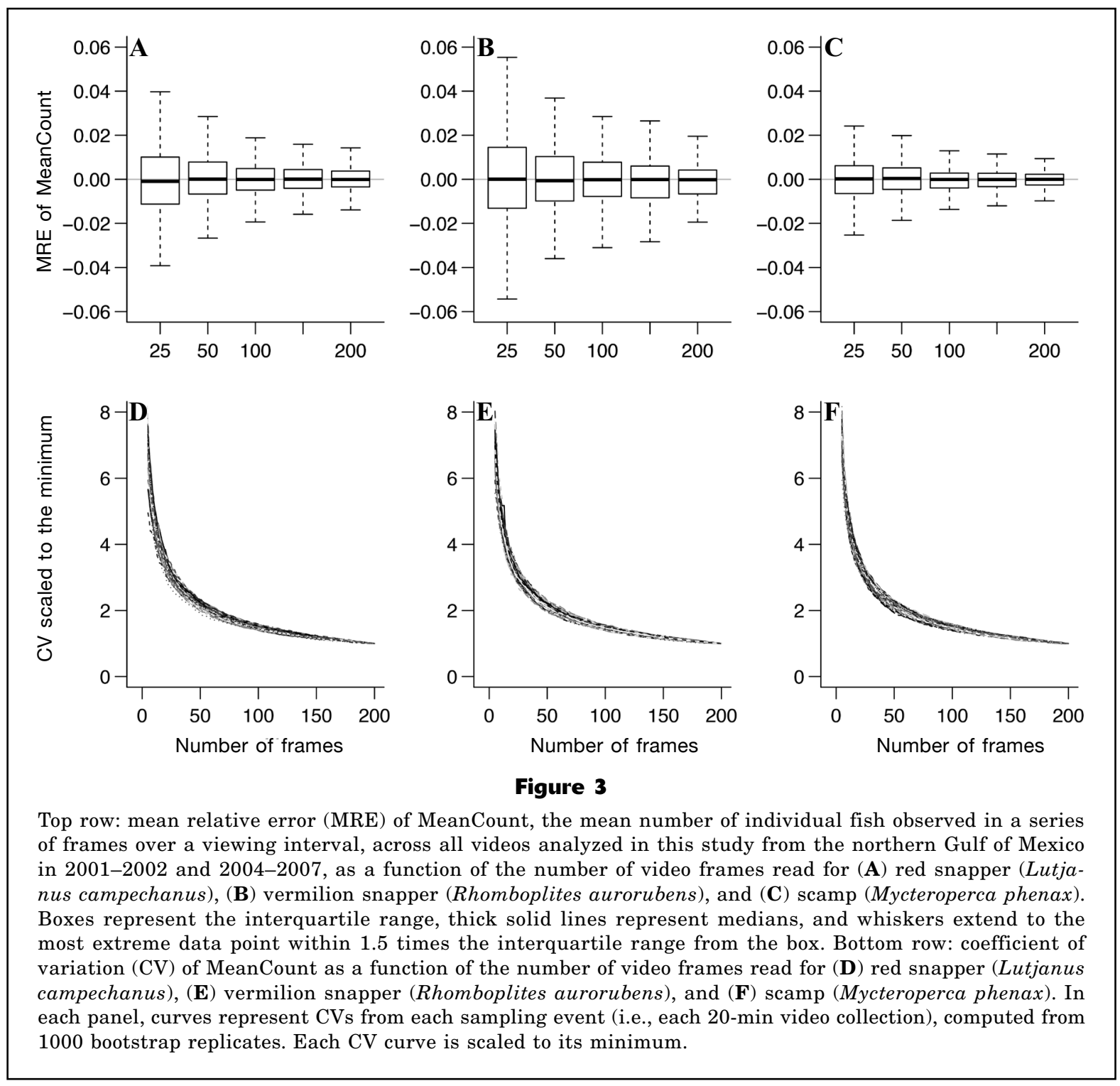

in 25 frames on the basis of the mean duration of each species in a video (estimated degrees of freedom [edf] $=1.5 ; F=36.6 ; P<0.0001)$, mean number of individuals in a video $(\mathrm{edf}=1.0 ; F=43.9 ; P<0.0001)$, or their interaction (edf $=7.8 ; F=0.7 ; P=0.004$ ). Species were observed with higher probability as their mean time in the videos increased; however, this probability saturated near 1.0 for mean times of $100 \mathrm{~s}$ or more (Fig. 6A). Similarly, the probability of being observed increased as the mean number of individuals increased, but, the trend was nearly linear over the range of the predictor (Fig. 6B). The families of fishes that were most likely to be observed in 25 frames of video were the generally sedentary groups like jawfishes, bigeyes, squirrelfishes, angelfishes, and triggerfishes, and those families most likely to be missed were fast-moving groups like tunas and mackerels, barracudas, and jacks (Table 2).

\section{Discussion}

In many places around the world, underwater video has become a common approach to monitor the abundance and distribution of marine fish and invertebrate species and to quantify marine biodiversity (e.g., Heagney et al., 2007; Stobart et al., 2007; Brooks et al., 2011; Merritt et al., 2011; Gladstone et al., 2012). For many such studies, BRUVS have been used and have provided an index of the abundance of various species through the use of a stationary point-count with the MinCount method (Ellis and DeMartini, 1995; Willis et al., 2000; Murphy and Jenkins, 2010). Recent research has indicated that MeanCount is more linearly related to true abundance than is MinCount (Conn, 2011; Schobernd et al., 2014). To provide the next logical step in the evaluation of the MeanCount approach, 

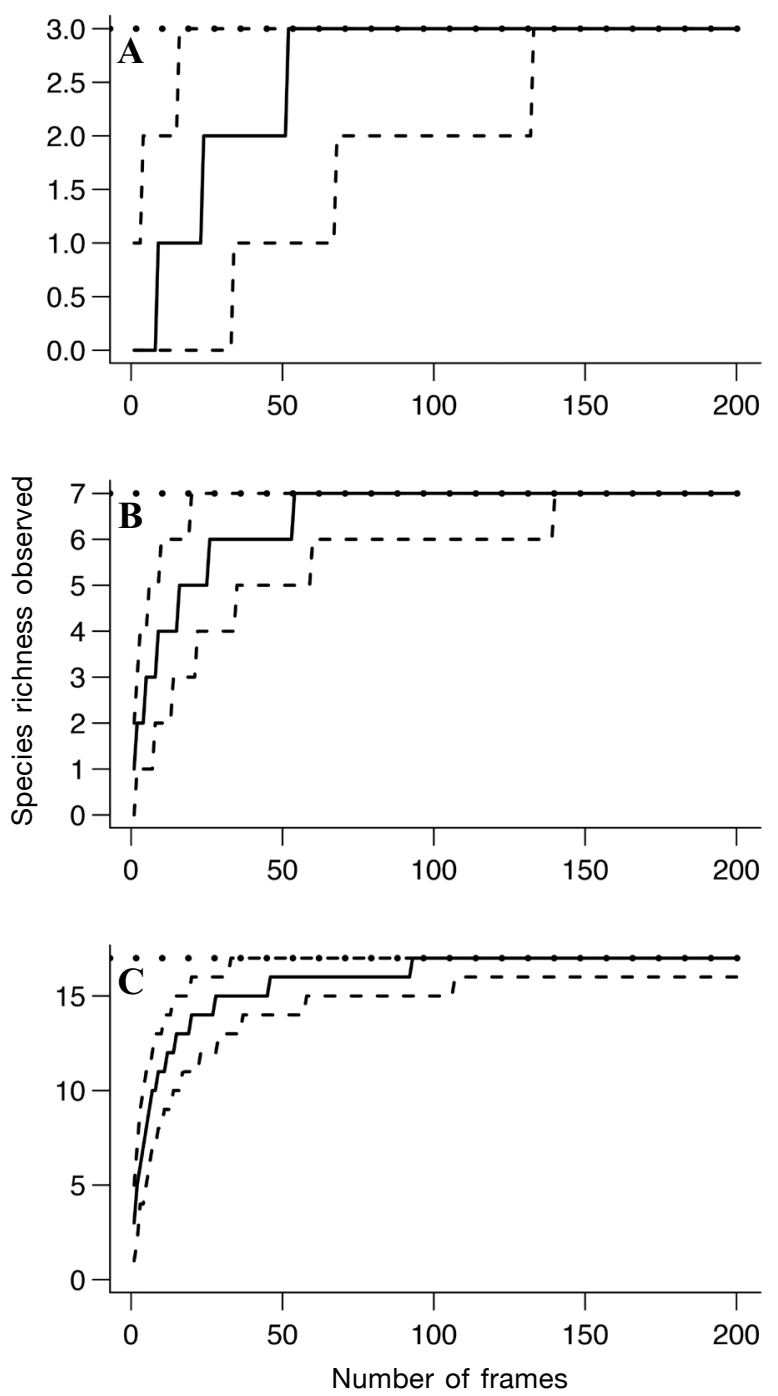

Figure 4

Examples of species richness (total number of species) observed as a function of the number of video frames that were read for this study of the use of video surveys to index abundance and diversity of reef fishes in the northern Gulf of Mexico in 2001-2002 and 2004-2007. Each panel is from a different 20-min video segment that was analyzed and selected to represent a relatively (A) low, (B) medium, or (C) high number of species. In each panel, the solid line is the median value from bootstrap replicates, the lower dashed line is the lower $5^{\text {th }}$ percentile, the upper dashed line is the $95^{\text {th }}$ percentile, and the dotted horizontal line is the total number of species observed in the full video (across all 1201 video frames).

we examined the tradeoff between time spent reading videos and the information obtained. In this study, we found that reading more frames decreased variability surrounding MeanCount for 3 reef fish species and in-

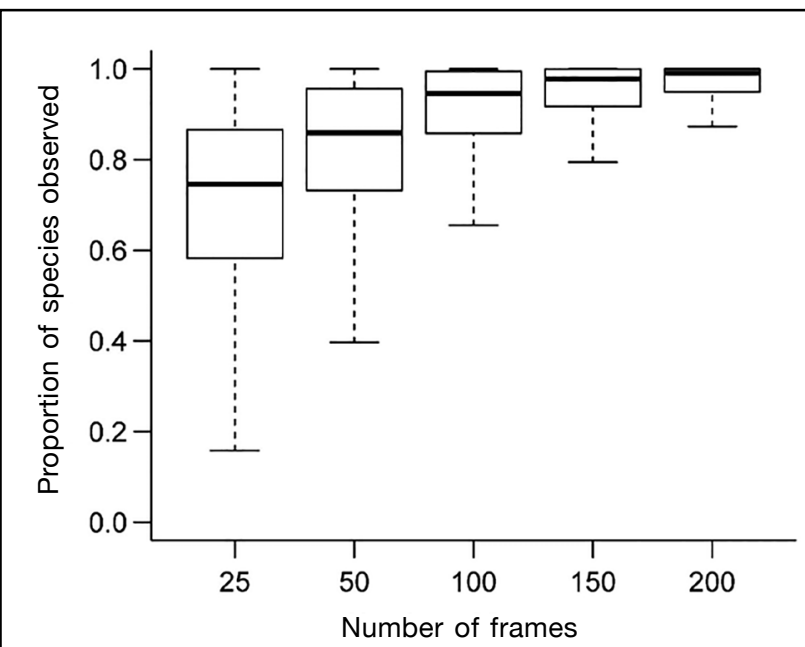

Figure 5

Proportion of species observed across all 20-min videos analyzed in this study as a function of the number of video frames that were read for this study of the use of video surveys to index abundance and diversity of reef fishes in the northern Gulf of Mexico in 2001-02 and 2004-2007. A value from each 20-min video was computed as the mean estimate of species richness (i.e., mean of the number of species observed across 1000 bootstrap replicates) divided by the total number of species known to be present in that video segment (i.e., observed in any of the 1201 video frames). Boxes represent the interquartile range, thick heavy lines represent medians, and whiskers extend to the most extreme data point within 1.5 times the interquartile range from the box.

creased the total number of species observed, but bias was negligible even when a small number of frames were read (e.g., $F=25$ ). These results will be useful to researchers in designing and tailoring their underwater video surveys to incorporate MeanCount for estimation of relative abundance or species richness.

Previous studies have shown that the number of taxa encountered in a wide variety of fisheries and wildlife monitoring studies is related to the spatial or temporal extent of sampling (Fuller and Langslow, 1984; St. John et al., 1990; Barker et al., 1993; Gledhill, 2001). We observed an inverse power relationship between CVs and number of frames read and an asymptotic relationship between the number of species observed and the number of frames read. Therefore, CVs decreased and the number of species observed increased dramatically as the number of frames read increased from 1 to 50 , but gains in precision were much more modest after that point. These results are similar to results from studies of stream fishes that have documented a threshold of sites sampled beyond which the increase in species observed was negligible (Angermeier and Smogor, 1995; Cao et al., 2001; de Freitas Terra et al., 2013). The number of frames that should 


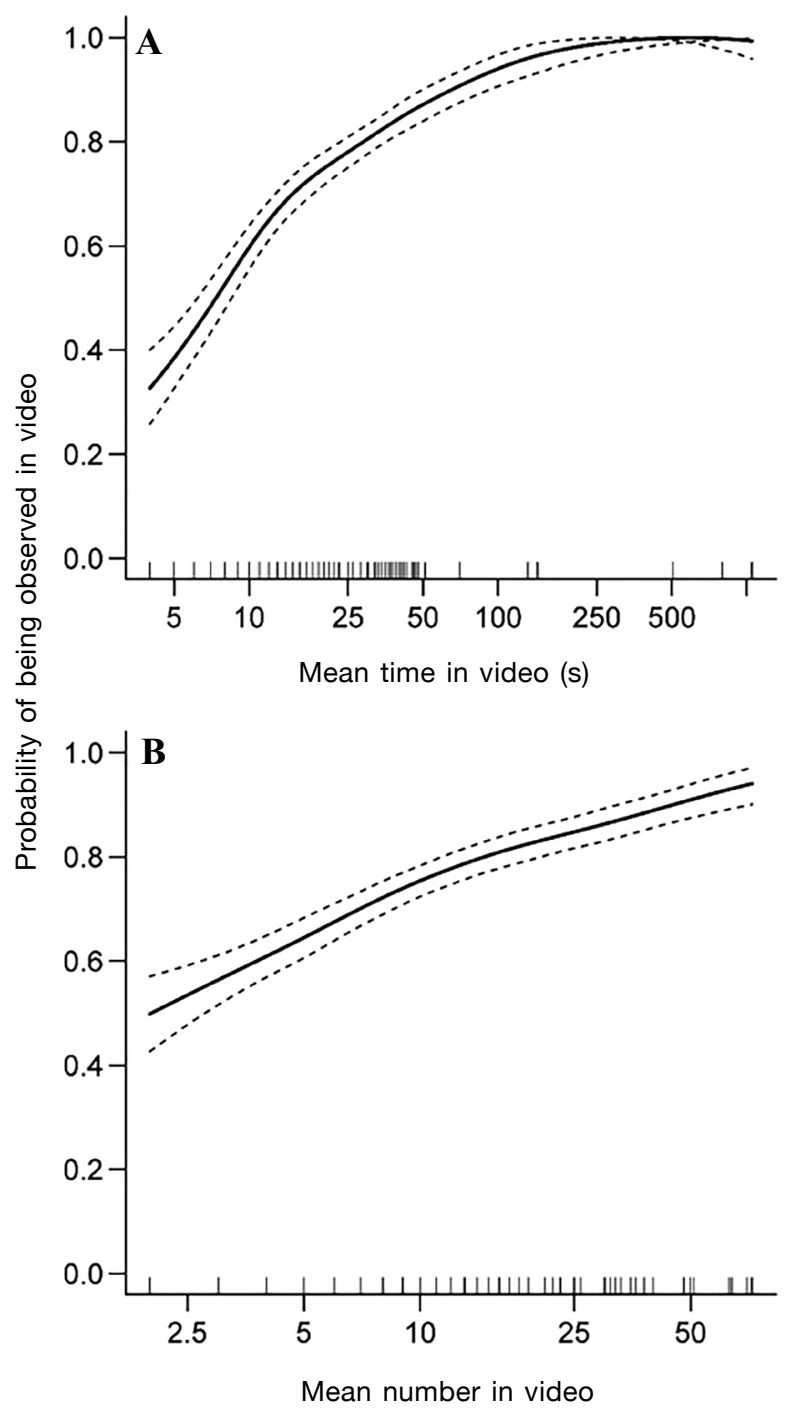

Figure 6

Relationship between the probability of a species being observed in a video segment and (A) its mean time in video or (B) the mean number of individuals of that species observed in each video. Included in the analysis were 90 reef fish species present in at least 10 videos in the National Marine Fisheries Service's reef fish video survey conducted in the northern Gulf of Mexico in 2001-2002 and 2004-2007 as part of its Southeast Area Monitoring and Assessment Program. The solid black lines indicate fitted relationships from a generalized additive model, the dashed lines are 95\% confidence intervals, and the tick marks on the $x$-axis show the distribution of values from the 90 species that were included in this analysis.

be read is likely study-specific and would depend on the total number of videos to be read, the relative importance of rare species, the total resources available for video reading, and time constraints for video read- ing (Gledhill, 2001). Our results indicate that reading approximately 50 frames from each video may provide a reasonable compromise between costs and information gained, if one can accept that about $14 \%$ of species would be missed at each site compared with a reading of all frames in an entire 20-min video segment.

As shown by our GAM results, behavioral characteristics largely determined how likely a species was to be observed or missed in a subset of video frames. Whether a species is observed in a subset of video frames is almost entirely dependent on 2 behavioral characteristics: 1) the mean duration of time spent by each fish in the video viewing area and 2) the mean number of individuals present in each video. Fast-swimming and relatively infrequent fishes, such as tunas, mackerels, barracudas, and jacks, were the ones most likely to be missed and, therefore, tended to be underrepresented in estimates of species richness. These same taxa also had higher absolute CVs around indices of abundance than those for fishes like groupers and snappers that were observed more frequently. We also showed that CVs from observations of a fast-moving, schooling species (vermilion snapper) were more than twice as high as CVs for a slow-moving, nonschooling species (scamp), but the relative pattern of CVs was the same for both species. Clearly, researchers must carefully consider the behavior of their target species when designing a BRUVS sampling strategy with a MeanCount approach, for instance, by allocating significantly more video-reading effort if fast-moving, infrequently encountered species are targeted.

We estimated the proportion of species observed in a subset of frames compared with the number observed in all frames of a 20 -min video segment, but note that reading all frames in a 20 -min video segment likely underestimates all the species present at a site. For instance, Gledhill (2001) showed that approximately $68 \%$ of reef fish taxa in the Gulf of Mexico that were observed in a continuous 60 -min video segment were observed in analysis of a 20-min segment. Furthermore, given the exclusively diurnal sampling in our study, nocturnal fishes were likely poorly detected, as were small, cryptic species (Collette et al., 2003; SmithVaniz et al., 2006; Williams et al., 2006). Therefore, our results (from an approach for which a subset of frames was read) should be interpreted as a reduction in species observed compared with results from reading of a 20-min video segment, not a comparison with the true species richness at a site.

Researchers could consider approaches that account for the fact that all video reading methods likely miss some reef fish species that are actually present at a site. First, occupancy or $N$-mixture modeling approaches can estimate detection or capture probabilities separately from the underlying distribution or abundance of a species (MacKenzie et al., 2002; Royle, 2004), but multiple site visits may be necessary each year (Issaris et al., 2012) unless spatial autocorrelation is modeled (Johnson et al., 2013). Second, if the emphasis is on es- 
timation of species richness over an entire study area, species accumulation (i.e., rarefaction) curves may be a useful approach (e.g., Nichols et al., 1998; Thompson et al., 2003). Species accumulation curves and related approaches (Angermeier and Smogor, 1995) may be especially useful in diverse systems with many rare species (Green and Young, 1993; Gotelli and Colwell, 2001).

Our study design included several simplifications. First, with our bootstrap procedure frames were selected at random for analysis. Alternative approaches may select frames systematically, either with fixed intervals (e.g., one frame every 30 s; Bacheler et al., 2013) or through adaptive sampling. Second, we estimated the proportion of species observed in a subset of frames in relation to all of the species observed in each 20 -min video segment. Ideally, our estimates would have been compared with the total number of species occupying the site, but true species richness at each site was unknown (Gotelli and Colwell, 2001). Third, we lacked information on current direction or magnitude; therefore, we were unable to estimate the size or shape of the bait plume, information that can be important in determining the catch or counts of fishes made through the use of baited gears (Collins et al., 2002; Jamieson et al., 2006). Fourth, we did not account for temporal autocorrelation (i.e., samples taken closer in time are likely more similar than those taken further apart; Strachan and Harvey, 1996) when analyzing frames within a particular video. Temporal autocorrelation violates the standard statistical assumption of independence among observations and, when present, may affect the estimated CVs. Temporal correlation is problematic for characterization of diel or seasonal variability but not for quantification of the density or number of species captured in a video. Temporal correlation could be minimized or avoided in practice by not choosing frames clustered in time. Fifth, our study would have been more informative if the costs of reading video frames were known, allowing for explicit cost-benefit analyses related to optimum sample sizes (Cochran, 1977; Thompson, 1992). However, these video data were recorded in a time in-time out format and not by individual frames, and, therefore, the costs of reading each frame could not be estimated.

MeanCount, computed from a sequence of video frames, has been shown to track linearly with true abundance at a site (Conn, 2011; Schobernd et al., 2014) - a critically important issue when standardizing survey data to produce abundance indices for use in stock assessment models (Maunder and Punt, 2004). Our study is the first, however, to document how the number of frames read can relate to $\mathrm{CVs}$ around MeanCount for reef fish species and the proportion of reef fish species observed at a site. Previous research has documented the general relationship between the spatial or temporal extent of sampling and CVs or the number of species observed (Fuller and Langslow, 1984; St. John et al., 1990; Barker et al., 1993; Gledhill, 2001). Similarly, we showed that the number of frames read was negatively related to $\mathrm{CVs}$ and positively related to the proportion of species observed. More important, however, both relationships were nonlinear and indicate that the information gain slowed substantially after reading approximately 50 frames. Video studies that apply the MeanCount approach to other systems could use our GAM results to help broadly understand how many frames to read, accounting for the behaviors of the species of interest.

\section{Acknowledgments}

We thank M. Campbell, C. Gledhill, A. Pollack, and the Pascagoula laboratory of the NOAA Southeast Fisheries Science Center for providing access to the Gulf of Mexico reef fish video data, the staff and crew members who participated in data collection, and the Southeast Area Monitoring and Assessment Program for funding. We also thank M. Campbell, A. Chester, P. Conn, A. Hohn, T. Kellison, P. Marraro, Z. Schobernd, and 3 anonymous reviewers for comments on previous versions of this manuscript.

\section{Literature cited}

Al-Chokhachy, R., P. Budy, and M. Conner.

2009. Detecting declines in the abundance of a bull trout (Salvelinus confluentus) population: understanding the accuracy, precision, and costs of our efforts. Can. J. Fish. Aquat. Sci. 66:649-658. doi: 10.1139/F09-026.

Angermeier, P. L., and R. A. Smogor.

1995. Estimating number of species and relative abundances in stream-fish communities: effects of sampling effort and discontinuous spatial distributions. Can. J. Fish. Aquat. Sci. 52:936-949. doi: 10.1139/f95-093.

Bacheler, N. M., C. Schobernd, Z. Schobernd, W. A. Mitchell, D. Berrane, G. T. Kellison, and M. J. M. Reichert.

2013. Comparison of trap and underwater video gears for indexing reef fish presence and abundance in the southeast United States. Fish. Res. 143:81-88. doi: 10.1016/j.fishres.2013.01.013.

Barker, R. J., J. R. Sauer, and W. A. Link.

1993. Optimal allocation of point-count sampling effort. Auk 110:752-758.

Brooks, E. J., K. A. Sloman, D. W. Sims, and A. J. Danylchuk. 2011. Validating the use of baited remote underwater video surveys for assessing the diversity, distribution and abundance of sharks in the Bahamas. Endang. Spec. Res. 13:231-243. doi: 10.3354/esr00331.

Cao, Y., D. P. Larsen, and R. M. Hughes.

2001. Evaluating sampling sufficiency in fish assemblage surveys: a similarity-based approach. Can. J. Fish. Aquat. Sci. 58:1782-1793. doi: 10.1139/f01-120.

Cappo, M., P. Speare, and G. D'eath.

2004. Comparison of baited remote underwater video stations (BRUVS) and prawn (shrimp) trawls for assessments of fish biodiversity in inter-reefal areas of the Great Barrier Reef Marine Park. J. Exp. Mar. Biol. Ecol. 302:123-152. doi: 10.1016/j.jembe.2003.10.006. 
Carpenter, K. E. (ed.)

2002. The living marine resources of the Western Central Atlantic. Vol. 1: introduction, molluscs, crustaceans, hagfishes, sharks, batoid fishes, and chimaeras. FAO species identification guide for fishery purposes and American Society of Ichthyologists and Herpetologists Special Publication 5, 600 p. FAO, Rome.

Cochran, W. G.

1977. Sampling techniques, 3rd ed., 428 p. Wiley, New York.

Collette, B. B., J. T. Williams, C. E. Thacker, and M. L. Smith. 2003. Shore fishes of Navassa Island, West Indies: a case study on the need for rotenone sampling in reef fish biodiversity studies. Aqua 6:89-131.

Collins, M. A., C. Yau, F. Guilfoyle, P. Bagley, I. Everson, I. G.

Priede, and D. Agnew.

2002. Assessment of stone crab (Lithodidae) density on the South Georgia slope using baited video cameras. ICES J. Mar. Sci. 59:370-379. doi: 10.1006/ jmsc.2001.1167.

Conn, P. B.

2011. An evaluation and power analysis of fishery independent reef fish sampling in the Gulf of Mexico and U.S. south Atlantic. NOAA Tech. Memo. NMFSSEFSC-610, $32 \mathrm{p}$.

de Freitas Terra, B., R. M. Hughes, and F. G. Araújo.

2013. Sampling sufficiency for fish assemblage surveys of tropical Atlantic forest streams, southeastern Brazil. Fisheries 38:150-158. doi: 10.1080/03632415.2013.775572.

Ellis, D. M., and E. E. DeMartini.

1995. Evaluation of a video camera technique for indexing the abundances of juvenile pink snapper, Pristipomoides filamentosus, and other Hawaiian insular shelf fishes. Fish. Bull. 93:67-77.

Fuller, R. J., and D. R. Langslow.

1984. Estimating numbers of birds by point counts: how long should counts last? Bird Study 31:195-202. doi: 10.1080/00063658409476841.

Gladstone, W., S. Lindfield, M. Coleman, and B. Kelaher. 2012. Optimisation of baited remote underwater video sampling designs for estuarine fish assemblages. J. Exp. Mar. Biol. Ecol. 429:28-35. doi: 10.1016/j. jembe.2012.06.013.

Gledhill, C. T.

2001. Reef fish assemblages on the Gulf of Mexico shelfedge banks. Ph.D. diss., 193 p. Univ. South Alabama, Mobile, AL.

Gotelli, N. J., and R. K. Colwell.

2001. Quantifying biodiversity: procedures and pitfalls in the measurement and comparison of species richness. Ecol. Lett. 4:379-391. doi: 10.1046/j. 1461-0248.2001.00230.x.

Green, R. H., and R. C. Young.

1993. Sampling to detect rare species. Ecol. Appl. 3:351-356.

Heagney, E. C., T. P. Lynch, R. C. Babcock, and I. M. Suthers. 2007. Pelagic fish assemblages assessed using mid-water baited video: standardising fish counts using bait plume size. Mar. Ecol. Prog. Ser. 350:255-266. doi: 10.3354/ meps07193.

Hoese, H. D., and R. H. Moore.

1998. Fishes of the Gulf of Mexico: Texas, Louisiana, and adjacent waters, $2^{\text {nd }}$ ed., 416 p. Texas A\&M Univ. Press, College Station, TX.
Humann, P., and N. Deloach.

2002. Reef fish identification: Florida, Caribbean, Bahamas, $3^{\text {rd }}$ ed., 512 p. New World Publ., Jacksonville, FL.

Issaris, Y., S. Katsanevakis, M. Salomidi, K. Tsiamis, N. Katsiaras, and G. Verriopoulos.

2012. Occupancy estimation of marine species: dealing with imperfect detectability. Mar. Ecol. Prog. Ser. 453:95-106. doi: 10.3354/meps09668.

Jamieson, A. J., D. M. Bailey, H. J. Wagner, P. M. Bagley, and I. G. Priede.

2006. Behavioural responses to structures on the seafloor by the deep-sea fish Coryphaenoides armatus: implications for the use of baited landers. Deep-Sea Res. (I Oceanogr. Res. Pap.) 53:1157-1166. doi: 10.1016/j. dsr.2006.04.002.

Johnson, D. S., P. B. Conn, M. B. Hooten, J. C. Ray, and B. A. Pond.

2013. Spatial occupancy models for large data sets. Ecology 94:801-808. doi: 10.1890/12-0564.1.

Kimura, D. K., and D. A. Somerton.

2006. Review of statistical aspects of survey sampling for marine fisheries. Rev. Fish. Sci. 14:245-283. doi: 10.1080/10641260600621761.

Langlois, T. J., E. S. Harvey, B. Fitzpatrick, J. J. Meeuwig, G. Shedrawi, and D. L. Watson.

2010. Cost-efficient sampling of fish assemblages: comparison of baited video stations and diver video transects. Aquat. Biol. 9:155-168. doi: 10.3354/ab00235.

MacKenzie, D. I., J. D. Nichols, G. B. Lachman, S. Droege, J. A. Royle, and C. A. Langtimm.

2002. Estimating site occupancy rates when detection probabilities are less than one. Ecology 83:2248-2255. doi: 10.1890/0012-9658(2002)083[2248: ESORWD]2.0.CO;2.

Maunder, M., and A. Punt.

2004. Standardizing catch and effort data: a review of recent approaches. Fish. Res. 70:141-159. doi: 10.1016/j.fishres.2004.08.002.

McEachran, J., and J. D. Fechhelm.

1998. Fishes of the Gulf of Mexico, vol. 1, 1120 p. Univ. Texas Press, Austin, TX.

2005. Fishes of the Gulf of Mexico, vol. 2, 1014 p. Univ. Texas Press, Austin, TX.

Merritt, D., M. K. Donovan, C. Kelley, L. Waterhouse, M. Parke, K. Wong, and J. C. Drazen.

2011. BotCam: a baited camera system for nonextractive monitoring of bottomfish species. Fish. Bull. 109:56-67.

Murphy, H. M., and G. P. Jenkins.

2010. Observational methods used in marine spatial monitoring of fishes and associated habitats: a review. Mar. Freshw. Res. 61:236-252. doi: 10.1071/ MF09068.

Nichols, J. D., T. Boulinier, J. E. Hines, K. H. Pollock, and J. R. Sauer.

1998. Inference methods for spatial variation in species richness and community composition when not all species are detected. Conserv. Biol. 12:1390-1398.

$\mathrm{R}$ Core Team.

2012. R: A language and environment for statistical computing. R Foundation for Statistical Computing, Vienna, Austria. [Available from http://www.R-project. org/, accessed 31 March 2014.] 
Rotherham, D., A. J. Underwood, M. G. Chapman, and C. A. Gray.

2007. A strategy for developing scientific sampling tools for fishery-independent surveys of estuarine fish in New South Wales, Australia. ICES J. Mar. Sci. 64:15121516. doi: 10.1093/icesjms/fsm096.

Royle, J.A.

2004. $N$-mixture models for estimating population size from spatially replicated counts. Biometrics 60:108-115.

Schobernd, Z. H., N. M. Bacheler, and P. B. Conn.

2014. Examining the utility of alternative video monitoring metrics for indexing reef fish abundance. Can. J. Fish. Aquat. Sci. 71:464-471. doi: 10.1139/ cjfas-2013-0086.

Silveira, L., A. T. A. Jacomo, and J. A. F. Diniz-Filho.

2003. Camera trap, line transect census and track surveys: a comparative evaluation. Biol. Conserv. 114: 351-355. doi: 10.1016/S0006-3207(03)00063-6.

Smith-Vaniz, W. F., H. L. Jelks, and L. A. Rocha.

2006. Relevance of cryptic fishes in biodiversity assessments: a case study at Buck Island Reef National Monument, St. Croix. Bull. Mar. Sci. 79:17-48.

Somerton, D. A., and C. T. Gledhill.

2005. Report of the National Marine Fisheries Service Workshop on Underwater Video Analysis. NOAA Tech. Memo. NMFS-F/SPO-68, 69 p.

St. John, J., G. R. Russ, and W. Gladstone.

1990. Accuracy and bias of visual estimates of numbers, size structure and biomass of a coral reef fish. Mar. Ecol. Prog. Ser. 64:253-262. doi: 10.3354/meps253253.

Strachan, I. B., and L. E. Harvey.

1996. Quantifying the effects of temporal autocorrelation on climatological regression models using geostatistical techniques. Can. J. Forest Res. 26:864-871. doi: 10.1139/x26-094.

Stobart, B., J. A. García-Charton, C. Espejo, E. Rochel, R. Goñi,
O. Reñones, A. Herrero, R. Crec'hriou, S. Polti, C. Marcos, S. Planes, and A. Pérez-Ruzafa.

2007. A baited underwater video technique to assess shallow-water Mediterranean fish assemblages: methodological evaluation. J. Exp. Mar. Biol. Ecol. 345:158174. doi: 10.1016/j.jembe.2007.02.009.

Thompson, S. K.

1992. Sampling, 1st ed., 343 p. Wiley-Interscience, New York.

Thompson, G. G., P. C. Withers, E. R. Pianka, and S. A. Thompson.

2003. Assessing biodiversity with species accumulation curves; inventories of small reptiles by pit-trapping in Western Australia. Austral Ecol. 28:361-383. doi: 10.1046/j.1442-9993.2003.01295.x.

Wells, R. J. D., K. M. Boswell, J. H. Cowan Jr., and W. F. Patterson III.

2008. Size selectivity of sampling gears targeting red snapper in the northern Gulf of Mexico. Fish. Res. 89:294-299. doi: 10.1016/j.fishres.2007.10.010.

Williams, J. T., L. Wantiez, C. Chauvet, R. Galzin, M. Harmelin-Vivien, E. Jobet, M. Juncker, G. Mou-Tham, S. Planes, and P. Sasal.

2006. Checklist of the shorefishes of Wallis Island (Wallis and Futuna French Territories, south-central Pacific). Cybium 30:247-260.

Willis, T. J., and R. C. Babcock.

2000. A baited underwater video system for the determination of relative density of carnivorous reef fish. Mar. Freshw. Res. 51:755-763. doi: 10.1071/MF00010.

Willis, T. J., R. B. Millar, and R. C. Babcock. 2000. Detection of spatial variability in relative density of fishes: comparison of visual census, angling, and baited underwater video. Mar. Ecol. Prog. Ser. 198:249260. doi: $10.3354 / \mathrm{meps} 198249$.

Wood, S. N.

2006. Generalized additive models: an introduction with R, 392 p. CRC Press, Boca Raton, FL. 